\title{
AVALIAÇÃO DA PÓS-GRADUAÇÃO NA UFC: AS CRÍTICAS DOS COORDENADORES DE PROGRAMAS À CAPES
}

\author{
POSTGRADUATE EDUCATION EVALUATION AT UFC: PROGRAM \\ COORDINATORS CRITICISM AGAINST CAPES
}

\author{
Ana Lúcia Vitoriano Lopes ${ }^{1}$ \\ Universidade do Minho - UM \\ Virgínio Isidro Martins Sá2 \\ Universidade do Minho - UM
}

\begin{abstract}
Resumo
A presente pesquisa buscou identificar a percepção dos coordenadores de pós-graduação de uma universidade em relação à avaliação de seus programas de pós-graduação promovido pela CAPES. O estudo realiza uma incursão na legislação norteadora sobre o tema e nas abordagens teóricas acerca da avaliação educacional e, em específico, da pós-graduação stricto sensu. Trata-se de pesquisa descritiva, qualitativa delineando-se como estudo de caso. Os dados são provenientes de survey que foram submetidos a análise descritiva e análise de conteúdo (qualitativa). O lócus da pesquisa é a UFC e seus programas de pós-graduação avaliados em 2010 e 2013, tendo a participação dos respectivos coordenadores. Os resultados revelam que o modelo de avaliação adotado pela CAPES, com base na classificação de programas hierarquizados por notas e peso, é bem aceito. As críticas ao modelo de avaliação concentram-se na padronização dos critérios de avaliação da CAPES, que desconsidera as diferenças regionais e com relação ao estímulo à competitividade positiva entre as áreas de conhecimento.
\end{abstract}

Palavras-chave: Pós-graduação - Avaliação; Avaliação Educacional; Universidade Federal do Ceará (UFC).

\footnotetext{
1 Doutoranda em Ciências da Educação, área de conhecimento de Organização e Administração Escolar, do Instituto de Educação, Universidade do Minho, Braga-Portugal. Mestre em Administração de Empresas com ênfase em Administração de Recursos Humanos pela Universidade Federal do Ceará. Especialista em Administração Universitária pela Escola Interamericana de Administração Pública da Fundação Getúlio Vargas e graduada em Administração pela Universidade Estadual do Ceará.

2 Atualmente é o diretor da Licenciatura em Educação. Integra a equipa de investigadores do Centro de Investigação em Educação- CIEd (Universidade do Minho). Os seus principais interesses investigativos incluem a Administração Educacional, a Avaliação Institucional; as Políticas Educativas e a Sociologia das Organizações Educativas. É membro de diversas associações científicas, integrando atualmente os corpos sociais do Fórum Português de Administração Educacional. É autor e coautor de diversos trabalhos académicos (livros, capítulos de livros e artigos em revistas científicas, produzidos no âmbito dos seus interesses investigativos), publicados no país e no estrangeiro.
} 


\section{Abstract}

This research sought to identify the perception of postgraduate program coordinators at a university in relation to the evaluation of their postgraduate programs, promoted by CAPES. The study makes a foray into the guiding legislation on the subject and into the theoretical approaches about educational assessment and, in particular, about stricto sensu postgraduate studies. This is a descriptive, qualitative research, outlined as a case study. The data comes from a survey that was submitted to descriptive analysis and content analysis (qualitative). The focus of the research is the UFC and its postgraduate programs, considering the results of the CAPES assessment in 2013 compared to the results of the 2017 assessment, with the participation of the respective coordinators. The results reveal that the evaluation model adopted by CAPES, based on the classification of programs ranked by grades and weight, is well accepted by the investigated academic community. Criticisms of the evaluation model focus on the standardization of CAPES' evaluation criteria, which disregards regional differences and with regard to encouraging positive competitiveness between areas of knowledge.

Keywords: Postgraduate education - Evaluation; Educational evaluation; Federal University of Ceara (UFC).

\section{INTRODUÇÃO}

As transformações ocorridas na economia mundial, na ciência, e os efeitos da globalização, além das lógicas da competitividade, das inovações tecnológicas e das mudanças sociais, vêm se refletindo nas organizações. As universidades como organizações educacionais, onde se veem configuradas novas relações e práticas de gestão, marcadas pelo signo da competência acadêmica, científica, tecnológica e humana, desempenham importante papel no cenário científico, econômico, tecnológico, social e humanístico dos países que as mantêm.

A universidade se configura como um sistema diversificado de concepções teóricas, compondo-se de vários segmentos organizacionais com múltiplas finalidades, em consonância com uma prática administrativa que dinamiza, por intermédio de um número incontável de interfaces, partilhas e confrontos postos por seus integrantes, caracterizandose como uma organização complexa. O resultado desse sistema complexo reflete a existência de uma universidade marcada, no contexto interno, por contradições e tradições e, no contexto externo, por um processo de transição, mudanças e superação.

Uma perspectiva crítica em relação às novas ideias e diretrizes para mudança da organização universidade, em face deste novo cenário, concretiza-se mediante as palavras: democracia, participação, competitividade, produtividade, avaliação e qualidade.

Neste contexto, exigem-se das Instituições de Educação Superior (IES) respostas aos desafios como desenvolvimento científico e tecnológico, melhoria da qualidade do ensino, formação dos profissionais qualificados para o atendimento das demandas 
imediatas do mundo do trabalho, além da formação qualificada para inovações, preservação e desenvolvimento da cultura, pesquisa de ponta, desenvolvimento sustentável, gestão inovadora, entre outras da mesma natureza. Para atender a esses desafios, a universidade deve se reconstruir como instituição social indispensável ao desenvolvimento da sociedade.

As IES, por conseguinte, devem prestar contas à sociedade e aos órgãos reguladores e financiadores da educação do País, mediante a avaliação dos seus processos e do impacto dos resultados em suas ações. Convém salientar que as organizações públicas de educação superior se deparam com a demanda crescente de alunos, além da restrição orçamentária e legislativa da gestão administrativa do governo federal.

Nesse sentido, percebe-se que, para superar os desafios e atender à demanda por resultados, são fundamentais as atitudes e os procedimentos dos gestores da educação superior. Para isso, os gestores necessitam, rotineiramente, de informações que possibilitem dar apoio ao processo de tomada de decisão (Mcgee e Prusak, 1994; Hammond, Keeney e Raiffa, 2017 e Bazerman, 2014). McGee e Prusak (1994, p. 180) consideram indissociável o processo de tomada de decisão com a qualidade da informação produzida. Ressaltam, ainda, que "o papel do executivo na organização é tomar decisões sobre as atividades diárias que levem ao sucesso num futuro incerto". Comentam, também, que "essa sempre foi uma tarefa intimamente ligada à informação" e, ainda, que o slogan do moderno administrador poderia ser: "se pelo menos tivéssemos mais dados".

Acompanhando o processo de expansão, em 2016, a Instituição Federal de Ensino Superior (IFES), lócus dessa pesquisa, a Universidade Federal do Ceará (UFC), contava com 117 cursos de graduação, totalizando 26.225 alunos matriculados na modalidade presencial e 2.683 alunos na modalidade semipresencial; 58 cursos de mestrado acadêmico e 13 mestrados profissionais, sendo 5 em rede, com 3.298 alunos; 45 cursos de doutorado, sendo 5 em rede, com 2.694 alunos, totalizando 116 cursos de pós-graduação stricto sensu, e 8 cursos de pós-graduação lato sensu, com 499 alunos.

Partindo da consideração de que os cursos de pós-graduação stricto sensu constituem um lugar privilegiado de produção do conhecimento, dada a centralidade que a pesquisa científica deve neles assumir, os resultados da avaliação dos órgãos reguladores vêm influenciando a complexidade e a dinâmica dos próprios programas de pós-graduação, ao mesmo tempo em que recebe influências deles. Diante deste cenário, surge o questionamento norteador desta pesquisa: Como a avaliação da Coordenação de 
Aperfeiçoamento de Pessoal de Nível Superior (CAPES) é percebida para a gestão dos programas de pós-graduação da UFC pelos próprios coordenadores?

Portanto, este estudo tem como objetivo geral identificar como os coordenadores de programas de pós-graduação da UFC percebem a avaliação externa realizada pela Agência Executiva do Ministério da Educação (MEC) para o desenvolvimento de seus cursos. $O$ estudo realiza uma incursão na legislação norteadora sobre o tema, abordagens teóricas acerca da avaliação educacional e entrevistou os coordenadores desses programas, constituindo-se numa pesquisa de abordagem qualitativa com delineamento de estudo de caso.

Acredita-se que tais discussões fortalecem a articulação entre os processos de avaliação e a gestão das unidades acadêmicas e administrativas da universidade em foco. É possível, assim, desencadear um processo de ação-reflexão sobre o constante vir-a-ser das IFES diante de sua autonomia e visão de realização acadêmica por um lado e, de outro lado, o financiamento e a cobrança de resultados pelo Estado e pela sociedade, agentes externos, em tese, representados pela CAPES.

\section{REFERENCIAL TEÓRICO DA AVALIAÇÃO EDUCACIONAL E REGULAÇÃO DA AVALIAÇÃO DA PÓS-GRADUAÇÃO}

A avaliação, no sentido lato, constitui atividade corriqueira, que se faz todos os dias, sem recorrer a nenhum procedimento sistemático, mas com a intenção de emitir um juízo de valor sobre algo, ainda que sem base explícita (AGUILAR \& ANDER-EGG, 1994). Enquanto isso, a avaliação no sentido stricto, ou seja, formal, requer procedimento sistematizado, métodos técnicos e científicos. Os autores deixam clara a noção de que entre a avaliação informal e a avaliação sistemática "não há uma diferença de propósitos, mas de métodos" (AGUILAR \& ANDER-EGG, 1994, p. 33).

Neste trabalho, refere-se à avaliação educacional no sentido stricto, ou seja, formal. Por ser sistemática, baseia-se no uso de método científico, para identificar, obter informação e julgar o mérito e o valor do objeto avaliado.

Cabe pontuar que a avaliação educacional apresenta interesses diversificados e conflitantes, pois, de um lado, estão os que defendem a visão mecanicista do processo avaliativo, empregam métodos quantitativos, com o objetivo de medir e classificar os resultados obtidos por meio de dados numéricos. Por ser estritamente quantitativo, 0 enfoque racionalista produz informações estatísticas rigorosamente confiáveis e independentes do modo como os dados foram coletados e de quem os coletou. De outro 
lado, estão os que veem o mundo sob a óptica formativa. Nesse olhar, o conhecimento está situado no campo semântico da subjetividade, pois o que importa é a visão de conjunto, as relações entre meios e fins, os questionamentos e, fundamentalmente, a participação.

Dias Sobrinho (2008) enfatizam que o interesse pela avaliação educacional não deve ocorrer somente em relação ao seu potencial de transformação qualitativa, de melhoramento pedagógico e de maior eficiência da gestão, mas também em função das exigências de regulação e de controle por parte dos governos e órgãos financiadores. Segundo os autores, o objeto central de uma avaliação educativa são os fins.

No Brasil, como em outros países, em momentos diferenciados, encontram-se o enfoque da avaliação educativa (formativa) e o da avaliação quantitativista (produtivista).

Do ponto de vista de Dias Sobrinho (2003b), a avaliação educativa induz à reflexão, ao questionamento da cultura educativa, à criatividade, valorizando a formação da sociedade. Por ser de natureza interna, enfatiza os aspectos da autoavaliação, baseandose nos princípios de participação, gestão democrática e melhoria educacional. Enquanto isso, a avaliação quantitativista é voltada para que a avaliação seja econômica, no sentido de valorizar a regulação, o controle, a hierarquização, na busca de eficiência, produtividade e estabelecimento de ranques para efeitos comparativos entre instituições, programas e cursos. Essa perspectiva de avaliação, de natureza externa, utiliza-se de metodologias em larga escala para recolha de dados estatísticos e quantitativos, a fim de controlar o sistema e as instituições educacionais, como sugere o processo avaliativo da pós-graduação realizado pela CAPES Os dois enfoques não pertencem exclusivamente ao campo da avaliação, mas da ciência, política, ideologia e vida em geral.

A avaliação é hoje uma política pública utilizada como estratégia de poder. Em outras palavras, afasta-se de seu significado primitivo de valor pedagógico e se transforma cada vez mais em um instrumento de aliança entre instâncias dos governos nacionais e organismos multilaterais a serviço da causa neoliberal (DIAS SOBRINHO, 2012, p. 1).

Consoante o autor supracitado, no Brasil, a avaliação quantitativista tem prevalecido, especialmente, na esfera da Administração Central e na mídia e está voltada para uma sociedade mercantil e competitiva. Partindo dessa premissa, tal modalidade relaciona-se com indicadores de competição, inspeção, credenciamento e classificação, dentre outros. Já no meio acadêmico, ainda de acordo com Dias Sobrinho (2003b), não se tem consenso das teorias, tampouco da prática avaliativa. Em suas análises, o autor reforça a necessidade de eliminar a polaridade entre as duas modalidades de avaliação.

A realidade universitária no tocante à avaliação é de desafios, desde os anos de 1970, quando a política educacional do regime civil-militar submeteu a educação à 
produção, com o propósito de modernizar o País por meio do desenvolvimento tecnológico, atrelado a um modelo econômico. Nesse período, estava em curso, por imposição legal, a implantação da chamada Reforma Universitária de 1968. Ao mesmo tempo que o governo militar pressionava a rede de universidades federais por maior racionalidade administrativa e no uso dos recursos públicos, iniciava-se o surto de expansão da rede de instituições de educação superior privadas (SOUSA \& SOUSA, 1998).

Nesse intervalo, o Ministério da Educação (MEC) promoveu seminários internacionais sobre pesquisa institucional, ao modo como então se traduziam os exercícios de autoavaliação. Então, realizou amplo estudo sobre a implantação da reforma educacional nas universidades federais. Essas iniciativas mostraram a necessidade de aprofundar os estudos sobre avaliação, no intuito de dar visibilidade aos processos avaliativos até então limitados aos aspectos organizacionais e de administração geral. Nesse ínterim, o MEC, para estimular a melhoria do ensino-aprendizagem, criou o Programa de Apoio ao Desenvolvimento do Ensino Superior (Pades) e o Programa Institucional de Capacitação Docente (PICD). Em 1976, a CAPES iniciou a experiência de avaliação externa dos programas de pós-graduação (SOUSA \& SOUSA, 1998).

Consoante informa Dias Sobrinho (2003a), a crise econômica mundial e o esgotamento do modelo militar brasileiro, nos anos 1980, trouxeram à tona o tema avaliação da educação superior como instrumento de base para orientar a distribuição de recursos públicos e a imposição da racionalidade e da eficiência. Nesses anos, críticas à universidade serviram de base ao confronto entre defensores do projeto do governo civilmilitar e a resistência dos setores envolvidos com a redemocratização do País.

Nesse meio-tempo, foram retomadas as discussões sobre autonomia das universidades, mormente das públicas, em especial no que se refere à administração e às finanças. Nos debates, sempre se explorava o argumento da responsabilidade como contrapartida da autonomia, responsabilidade, compreendendo a prestação de contas aliada à garantia da melhoria da qualidade dos serviços ofertados à sociedade (Sousa \& Sousa, 1998).

Dias Sobrinho (2003b) explica que, nos anos de 1980, dois programas de avaliação foram, sem êxito, implantados no Brasil: o Programa de Avaliação da Reforma Universitária (Paru), criado em 1983, para priorizar a gestão das instituições de Ensino Superior e o processo de produção e disseminação do conhecimento, e o Grupo de Estudos para a Reforma do Ensino Superior (Geres), criado em 1986, com o objetivo de substituir os 
controles formais e burocráticos por procedimentos de avaliação de resultados. Os dois programas tiveram curta vigência em decorrência de insuficiente apoio político do MEC.

Com a promulgação da Constituição Federal de 1988 foram estabelecidas duas garantias às universidades. No artigo 207, o princípio da autonomia das universidades e, no artigo 209, a inclusão de forma definitiva da avaliação educacional, segundo a qual:

O ensino é livre à iniciativa privada, atendidas as seguintes condições:

I - cumprimento das normas gerais da educação nacional;

II - autorização e avaliação de qualidade pelo Poder Público.

(BRASIL, 1988, artigo 209; grifa-se).

A avaliação educacional ganhou maior importância nos anos de 1990, particularmente desde 1995, com a ampliação das políticas que favorecem a privatização, a autonomia como contrapartida da avaliação de resultados e a valorização da ideologia da excelência, da eficiência, da produtividade e da gestão eficaz. Segundo Dias Sobrinho (2003b, p. 75), desde esse período, o MEC deu ênfase à avaliação como "controle e instrumentalização de suas políticas reformistas". Este período foi chamado de "década da avaliação", caracterizado por intensos debates, no espaço político de conflito e tensão em torno do tema.

Para Dias Sobrinho (2003b), a avaliação como estratégia de Estado se fortalece com a adesão dos governos brasileiros às políticas neoliberais e ganhou legalidade com as Diretrizes e Bases da Educação Nacional (LDB), Lei no 9.394/96 (Brasil, 1996), e o conjunto de documentos legais, normas, práticas que dela decorrem. Está condicionada à jurisprudência do Conselho Nacional de Educação, que constitui instância competente para aprovar estatutos e regimento geral.

Em 14 de abril de 2004, foi instituído o Sistema Nacional de Avaliação da Educação Superior (Sinaes) pela Lei no 10.861 (BRASIL, 2004), com o objetivo de "assegurar o processo nacional de avaliação das instituições de educação superior, dos cursos de graduação e do desempenho acadêmico de seus estudantes" (artigo $1^{\circ}$ ). Foi apresentado, então, um novo modelo de avaliação de modo a solucionar os problemas imputados ao Exame Nacional de Curso.

A avaliação institucional divide-se em duas modalidades: autoavaliação e avaliação externa. Coordenada pela Comissão Própria de Avaliação (CPA) de cada instituição e orientada pelas diretrizes e pelo roteiro da autoavaliação institucional sugeridos, coordenados e supervisionados pela Comissão Nacional de Avaliação da Educação Superior (Conaes), órgão do Sinaes, a autoavaliação é realizada, permanentemente, com resultados a serem expressos a cada três anos, em que são identificadas fragilidades e 
potencialidades da instituição nas dimensões previstas em lei. A avaliação externa, no caso dos cursos de graduação, é feita por comissões de especialistas externos à instituição designados pelo Instituto Nacional de Estudos e Pesquisas Educacionais Anísio Teixeira (Inep). Exprime, como referência de padrão de qualidade para a Educação Superior, a avaliação institucional integrada por diversos instrumentos de avaliação: a autoavaliação conduzida pela Comissão Própria de Avaliação (CPA); a avaliação externa e os instrumentos de informação como o censo da educação superior e o cadastro de cursos e instituições.

Com relação à avaliação externa dos programas de pós-graduação, esta continuará mantida conforme decisão da CAPES.

O modelo CAPES atual de avaliação da pós-graduação decorre de todo o processo de sistematização e aperfeiçoamento tanto dos critérios como do próprio processo.

As primeiras avaliações eram realizadas anualmente. Após oito anos, passaram a ser bienais, periodicidade mantida de 1984 a 1998, quando o intervalo avaliado passou a ser trienal. É importante lembrar que, para realizar esta pesquisa, foi analisada a avaliação de 2013, considerando os anos de 2010, 2011 e 2012. Em 2013, teve início o primeiro período de acompanhamento da avaliação quadrienal exibida em setembro de 2017, considerando os anos de 2013, 2014, 2015 e 2016.

Os resultados da avaliação de 1998 foram amplamente divulgados no meio acadêmico e na mídia, com publicações retratando o desempenho dos cursos. Destacaramse os programas mais bem classificados, especialmente aqueles considerados de nível internacional. Até esse ano, a CAPES garantia o sigilo dos dados coletados e resultados obtidos na avaliação, que era feita a "portas fechadas", com informações assistemáticas, casuais (CAPES, 2002, p. 92). A divulgação da avaliação de 1998 foi acompanhada de muitos protestos, especialmente daqueles programas rebaixados no conceito.

A nova sistemática de avaliação dos programas foi modificada com a adoção de uma escala numérica e não mais conceitual, passando a ser composta por sete níveis de nota, de 1 a 7, estabelecendo as notas 6 e 7 como classificação de excelência. A não discriminação da qualidade dos programas, vista como esgotamento do sistema, foi responsável pela mudança.

Em virtude da multiplicidade de áreas de conhecimento, houve uma ampliação dessas áreas, pois a restrita divisão estava comprometendo as mais específicas. Introduziuse, também, a ideia de programa e não mais a de curso a ser avaliado. A introdução da pós-graduação de caráter profissional no Sistema Nacional de Pós-Graduação foi 
acompanhada de forte resistência pela comunidade acadêmica, assim como foi polêmico avaliar a qualidade da pós-graduação pela maior ou menor inserção internacional.

Outra grande mudança promovida na avaliação foi a adoção de critérios de pontuação para classificar a qualidade da produção intelectual dos programas de pós-graduação. Com esse propósito, a CAPES criou o Qualis - sistema de estratificação da produção intelectual. Os dados são obtidos por meio de um aplicativo, a Plataforma Sucupira, no qual os programas de pós-graduação informam a produção intelectual dos docentes e alunos.

Além dessas mudanças, a primeira avaliação quadrienal insere algumas inovações, como a inclusão de dados sobre os egressos dos cursos de mestrado e doutorado. Tal medida, segundo a diretoria de avaliação da CAPES, contribuirá para medir a inserção social dos programas de pós-graduação; os programas de mestrados profissionais serão avaliados por comissões distintas das comissões da área acadêmica, evitando que os programas profissionais sejam considerados com base nos mesmos critérios dos cursos de natureza acadêmica.

Em face de tais mudanças no processo avaliativo da CAPES, é recorrente o esforço dos dirigentes da CAPES em confrontar a pós-graduação com os novos desafios da sociedade brasileira e, de modo particular, do sistema de ensino superior, tanto para atender às diretrizes estabelecidas nos planos nacionais de pós-graduação, como em função das exigências do quadro econômico do Brasil, que saiu de um modelo de desenvolvimento econômico que preconizava intensiva participação do Estado e inaugurou um quadro de abertura da economia, com destaque para a "integração do ensino de pósgraduação com o setor empresarial e a sociedade" (BRASIL, 2010, p. 17).

\section{METODOLOGIA}

Trata-se de pesquisa descritiva com abordagem qualitativa e delineamento de estudo de caso, trabalhando com dados de survey que foram submetidos à análise descritiva por meio de tabelas e análise de conteúdo (qualitativa). O lócus da pesquisa é a UFC e seus programas de pós-graduação que contavam com duas avaliações trienais, tendo a participação dos respectivos coordenadores como respondentes.

A UFC possuía em 2016, quando da realização desta pesquisa, 77 programas de pós-graduação stricto sensu em funcionamento. Em todo caso, estavam aptos a participar da pesquisa apenas os programas que participaram da avaliação trienal 2013 e avaliação trienal 2010. Dessa forma, 52 programas foram considerados. Tratam-se, portanto, de 
programas de maior maturidade e experiência de participar de 2 avaliações trienais, assim em condições ótimas de avaliarem a própria CAPES e sua metodologia de avaliação.

Foram convidados os coordenadores destes programas de pós-graduação, sujeitos estes na linha de frente da gestão da pós-graduação e em relação direta junto à CAPES no atendimento a esta agência.

Estão detalhados na Tabela 1 o perfil dos respondentes: quantitativos de coordenadores selecionados para a pesquisa (Ns), número de sujeitos que efetivamente responderam ao questionário $(\mathrm{Nr})$ e as 9 (nove) grandes áreas de conhecimento estabelecidas pela CAPES na qual os programas foram agrupados.

Tabela 1 - Quantitativo dos sujeitos selecionados para a pesquisa versus respondentes distribuídos por áreas de conhecimento da CAPES

\begin{tabular}{lcccc}
\hline \multicolumn{1}{c}{$\begin{array}{c}\text { Áreas de } \\
\text { conhecimento }\end{array}$} & Ns & Nr & $\begin{array}{c}\text { Participação por área de } \\
\text { conhecimento } \\
(\%)\end{array}$ & $\begin{array}{c}\text { Participação por total de programas } \\
\text { integrantes da pesquisa } \\
\text { (\%) }\end{array}$ \\
\hline \hline Ciências exatas e da & 5 & 5 & 100 & 15,1 \\
terra & 5 & 4 & 80 & 12,1 \\
Ciências biológicas & 8 & 7 & 87,5 & 21,2 \\
Engenharias & 6 & 2 & 33,3 & 6,1 \\
Ciências da saúde & 6 & 4 & 66,6 & 12,1 \\
Ciências agrárias & 6 & 1 & 16,6 & 3,1 \\
Ciências humanas & 7 & 7 & 100 & 21,2 \\
Ciências sociais & 2 & 1 & 50 & 3,1 \\
aplicadas & 7 & 2 & 28,5 & 6,1 \\
Linguística, letras e & & $\mathbf{6 3 , 5}$ & $\mathbf{1 0 0}$ \\
artes & $\mathbf{3 2}$ & $\mathbf{3 3}$ & & \\
Multidisciplinar & Total & & & \\
\hline
\end{tabular}

Fonte: Dados da pesquisa (2017).

Com relação à participação, observa-se, na tabela 1, que 100\% dos coordenadores das áreas de conhecimento das ciências exatas e da terra (5) e ciências sociais aplicadas (7) responderam ao questionário. Na sequência, a área de engenharias obteve o segundo maior nível de participação (87,5\%), com 7 respondentes, seguida da área de ciências biológicas, com 4 (80\%) e de ciências agrárias com 4 (66,6\%). As áreas ciências da saúde, multidisciplinar e ciências humanas apresentaram o menor nível de participação na resposta aos questionários, com 33,3\% (2), 28,5\% (2), e 16,6\% (1), respectivamente.

No que se refere ao total de 33 respondentes, observa-se que 66,7\% (22) desta quantidade pertencem às áreas de ciências duras (ciências exatas e da terra, ciências biológicas, engenharias, ciências da saúde, ciências agrárias), enquanto somente 27,2\% (9) encontram-se na classificação de ciências brandas (ciências humanas e ciências sociais 
aplicadas) e 6,1\% (2) referentes à área multidisciplinar, que contempla programas tanto das ciências duras como das ciências brandas.

O instrumento de pesquisa utilizado neste trabalho foi o questionário. Tal instrumento foi viabilizado por meio de survey, encaminhado, portanto, de forma on-line aos coordenadores. Na survey foram feitas seis proposições afirmativas em relação à classificação dos programas por ranking de notas e pesos, se tal política: P1 - reflete a qualidade do programa, fazendo a distinção entre os melhores; P2 - identifica os pontos fortes e fracos, regulando melhor o desempenho do programa; P3 - estimula de forma positiva a competitividade entre as áreas de conhecimento; P4 - auxilia na tomada de decisões para definição de ações de melhoria dos programas; P5 - atribui pesos adequados a cada um dos itens avaliados: inserção social (10\%); corpo docente (20\%); corpo discente (30\%); produção intelectual (40\%) e P6 - discrimina o programa pelo caráter homogeneizador do modelo de avaliação. Os respondentes poderiam responder a cada uma das proposições com (P): a) discordo totalmente, b) discordo em parte, c) concordo em parte, d) concordo totalmente e e) não sei. As repostas foram analisadas por meio do Microsoft Office Excel, aplicativo de criação das planilhas.

Também constava nesse questionário questões abertas, na qual pedia-se que o respondente fizesse considerações que achasse pertinente. Essas repostas foram analisadas por meio da análise de conteúdo (qualitativa).

\section{RESULTADOS E DISCUSSÃO}

A seguir apresenta-se os resultados, na qual opta-se por trazer em tabelas para permitir visão do conjunto dos programas e como seus coordenadores responderam as proposições. Tais tabelas são apresentadas com os dados totais da pesquisa, em seguida com recortes para identificar percepções destes coordenadores em relação às proposições tratadas. As respostas de todos os participantes constam sintetizadas na Tabela 2. 
Tabela 2 - Percepção dos coordenadores da pós-graduação stricto sensu da UFC em relação à classificação dos programas por ranking de notas e pesos

\begin{tabular}{|c|c|c|c|c|c|c|c|c|c|c|c|c|c|}
\hline & \multirow{2}{*}{ Proposição } & \multicolumn{2}{|c|}{$\begin{array}{l}\text { Discordo } \\
\text { totalmente }\end{array}$} & \multicolumn{2}{|c|}{$\begin{array}{l}\text { Discordo } \\
\text { em parte }\end{array}$} & \multicolumn{2}{|c|}{$\begin{array}{l}\text { Concordo } \\
\text { em parte }\end{array}$} & \multicolumn{2}{|c|}{$\begin{array}{l}\text { Concordo } \\
\text { totalmente }\end{array}$} & \multicolumn{2}{|c|}{$\begin{array}{l}\text { Não } \\
\text { sei }\end{array}$} & \multicolumn{2}{|c|}{ Total } \\
\hline & & $f$ & $\%$ & $f$ & $\%$ & $F$ & $\%$ & $f$ & $\%$ & $f$ & $\%$ & $f$ & $\%$ \\
\hline $\mathrm{P} 1$ & $\begin{array}{l}\text { Reflete a qualidade do } \\
\text { programa, fazendo a distinção } \\
\text { entre os melhores }\end{array}$ & 1 & 3,0 & 3 & 9,1 & 19 & 57,6 & 10 & 30,3 & 0 & 0,0 & 33 & 100 \\
\hline P2 & $\begin{array}{l}\text { Identifica os pontos fortes e } \\
\text { fracos, regulando melhor o } \\
\text { desempenho do programa }\end{array}$ & 1 & 3,0 & 2 & 6,0 & 15 & 45,5 & 15 & 45,5 & 0 & 0,0 & 33 & 100 \\
\hline P3 & $\begin{array}{l}\text { Estimula de forma positiva a } \\
\text { competitividade entre as } \\
\text { áreas de conhecimento }\end{array}$ & 4 & 12,1 & 7 & 21,2 & 12 & 36,4 & 8 & 24,2 & 2 & 6,1 & 33 & 100 \\
\hline P4 & $\begin{array}{l}\text { Auxilia na tomada de } \\
\text { decisões para definição de } \\
\text { ações de melhoria dos } \\
\text { programas }\end{array}$ & 1 & 3,0 & 1 & 3,0 & 15 & 45,5 & 16 & 48,5 & 0 & 0,0 & 33 & 100 \\
\hline P5 & $\begin{array}{l}\text { Atribui pesos adequados a } \\
\text { cada um dos itens avaliados: } \\
\text { inserção social (10\%); corpo } \\
\text { docente (20\%); corpo } \\
\text { discente }(30 \%) ; \text { produção } \\
\text { intelectual }(40 \%)\end{array}$ & 2 & 6,1 & 3 & 9,0 & 16 & 48,5 & 10 & 30,3 & 2 & 6,1 & 33 & 100 \\
\hline P6 & $\begin{array}{l}\text { Discrimina o programa pelo } \\
\text { caráter homogeneizador do } \\
\text { modelo de avaliação }\end{array}$ & 3 & 9,1 & 7 & 21,2 & 14 & 42,4 & 5 & 15,2 & 4 & 12,1 & 33 & 100 \\
\hline
\end{tabular}

Fonte: Dados da pesquisa (2017).

Os resultados revelam que o sistema de avaliação da CAPES é bem aceito pela comunidade acadêmica investigada, uma vez que os resultados da escala concordo em parte $(57,6 \%)$ e concordo totalmente (30,3\%) perfazem um total de aproximadamente $90 \%$ dos respondentes, ou seja, 29 dos 33 respondentes entendem que o escalonamento dos programas por nota e peso reflete a qualidade do programa, fazendo a distinção entre os melhores (Proposição 1).

Além disso, quase a totalidade dos respondentes, ou seja, 45,5\% concordam em parte e $45,5 \%$ concordam totalmente com a ideia de que o escalonamento regula melhor 0 desempenho do programa, possibilitando identificar os seus pontos fortes e fracos, perfazendo um percentual de mais de $90 \%$ de concordância (P2), como também dá apoio ao processo de tomada de decisão, uma vez que na escala concordo em parte $(45,5 \%)$ e concordo totalmente $(48,5 \%)$ os respondentes revelam avaliação majoritária, em torno de 94\% (P4). Com relação a atribuir pesos adequados para cada item da avaliação, os resultados revelam que $48,5 \%$ dos respondentes concordam em parte e 30,3\% concordam totalmente, evidenciando um grau de concordância relevante em torno de $79 \%$ (P5), como 
pode ser visto pelo relato: "a nota 5 do programa de [...] reflete bastante a qualidade do que foi feito no último quadriênio" (coordenador 26, ciências sociais aplicadas).

Confrontando com as avaliações positivas em relação ao modelo em questão, chama a atenção o resultado da proposição (P3), devido ao percentual de discordância total $(12,1 \%)$ e em parte $(21,2 \%)$, em relação ao aspecto da avaliação como estímulo de forma positiva à competitividade entre as áreas de conhecimento. Semelhante ao que ocorre com a preposição $\mathrm{P} 6$, na qual $42,4 \%$ dos respondentes concordam em parte e 15,2\% totalmente com a ideia de que o modelo de avaliação da CAPES discrimina os programas pelo caráter homogeneizador do modelo em questão. Estes resultados vão de encontro ao pensamento de Dias Sobrinho (2003b), pois, segundo o autor, a competitividade e a discriminação não se caracterizam como uma avaliação educativa, pois "a avaliação com intencionalidade e função educativa deve ser desvinculada das medidas de financiamento e de qualquer mecanismo de premiação/punição e tampouco deve produzir hierarquizações de instituições" (Dias Sobrinho, 2003b, p. 43).

Cabe ressaltar que, dentre os princípios e diretrizes de avaliação da CAPES (2017, p. 51), destaca-se o caráter classificatório e comparativo entre as diferentes áreas de conhecimento,

a) A Avaliação é classificatória - estabelece diferentes níveis de qualidade de desempenho dos programas em cada área de avaliação - e, portanto, não deve gerar concentrações excessivas em quaisquer dos níveis da escala de notas.

b) A Avaliação é comparativa entre as diferentes áreas. Embora preserve e considere as especificidades das áreas, pauta-se pelo mesmo conjunto de quesitos e itens avaliativos e deve promover a equivalência de qualidade de desempenho entre programas com as mesmas notas nas distintas áreas de avaliação. Cada nota deve, portanto, corresponder ao mesmo nível de qualidade para todas as áreas de avaliação.

Tendo em vista que grande parte dos participantes manifestaram respostas de "concordo totalmente" e "concordo em parte", agrupamos esses coordenadores que, portanto, apoiam a política da CAPES por área de conhecimento, na tabela 3 . 0 agrupamento nesta tabela é tão somente para identificar as áreas mais anuentes à CAPES. 
Tabela 3 - Frequência de concordância na percepção dos coordenadores da pós-graduação stricto sensu da UFC em relação à classificação dos programas por ranking de notas e pesos, agrupados por área de conhecimento

\begin{tabular}{|c|c|c|c|c|c|c|c|c|c|c|c|}
\hline \multirow{2}{*}{\multicolumn{2}{|c|}{ Proposição }} & \multicolumn{9}{|c|}{ Área de conhecimento CAPES } & \multirow{2}{*}{ Total } \\
\hline & & EXT & AGR & $\mathrm{BIO}$ & ENG & SAU & CSA & HUM & LLA & MUL & \\
\hline$\overline{\mathrm{P} 1}$ & $\begin{array}{l}\text { Reflete a qualidade do } \\
\text { programa, fazendo a } \\
\text { distinção entre os melhores }\end{array}$ & 5 & 3 & 3 & 7 & 2 & 6 & - & 1 & 2 & 29 \\
\hline P2 & $\begin{array}{l}\text { Identifica os pontos fortes e } \\
\text { fracos, regulando melhor o } \\
\text { desempenho do programa }\end{array}$ & 5 & 4 & 3 & 7 & 2 & 6 & 1 & 1 & 1 & 30 \\
\hline P3 & $\begin{array}{l}\text { Estimula de forma positiva a } \\
\text { competitividade entre as } \\
\text { áreas de conhecimento }\end{array}$ & 3 & 3 & 2 & 5 & 2 & 3 & - & - & 2 & 20 \\
\hline P4 & $\begin{array}{l}\text { Auxilia na tomada de } \\
\text { decisões para definição de } \\
\text { ações de melhoria dos } \\
\text { programas }\end{array}$ & 5 & 4 & 3 & 7 & 2 & 6 & 1 & 1 & 2 & 31 \\
\hline P5 & $\begin{array}{l}\text { Atribui pesos adequados a } \\
\text { cada um dos itens } \\
\text { avaliados: inserção social } \\
\text { (10\%); corpo docente (20\%); } \\
\text { corpo discente (30\%); } \\
\text { produção intelectual (40\%) }\end{array}$ & 5 & 3 & 3 & 6 & 2 & 4 & - & 1 & 2 & 26 \\
\hline P6 & $\begin{array}{l}\text { Discrimina o programa pelo } \\
\text { caráter homogeneizador do } \\
\text { modelo de avaliação }\end{array}$ & 2 & 1 & 2 & 3 & 2 & 6 & 1 & - & 2 & 19 \\
\hline & $\begin{array}{l}\text { spondentes totais por área } \\
\text { de conhecimento }\end{array}$ & 5 & 4 & 4 & 7 & 2 & 7 & 1 & 1 & 2 & 33 \\
\hline
\end{tabular}

Fonte: Dados da pesquisa (2017).

Legenda: ciência exatas e da terra (EXT); ciências agrárias (AGR); ciências biológicas (BIO); engenharias (ENG); ciências da saúde (SAU); ciências sociais e aplicadas (CSA); ciências humanas, (HUM); linguística, letras e artes (LLA) e multidisciplinar (MUL).

Os resultados da tabela 3 revelam que o sistema de avaliação da CAPES, com base na classificação dos programas por ranking de notas e pesos, é avaliado positivamente pelos respondentes das 9 áreas de conhecimentos. A alta aceitação do modelo em questão é percebida pela frequência de "Concordância" (majoritária em 4 das 6 proposições), uma vez que variou de 26 a 31 respondentes nas proposições: reflete a qualidade do programa, com distinção dos melhores (P1); identifica pontos fortes e fracos (P2); auxilia na tomada de decisão (P4) e atribui pesos adequados a cada um dos itens avaliados (P5).

Em relação à hierarquização dos programas, estimular de forma positiva a competitividade entre as áreas de conhecimento(P3) e discriminar o programa pelo caráter homogeneizador (P6), os resultados não revelam unanimidade entre os coordenadores; a frequência de "concordância" foi de 20 e 19 respondentes respectivamente.

$\mathrm{Na}$ área de ciências exatas e da terra, todos os 5 respondentes concordam totalmente com as proposições P1, P2, P4 e P5, ou seja, a classificação dos programas por 
ranking de notas e peso é avaliada positivamente pelos respondentes dessa área. Em relação à hierarquização estimular de forma positiva a competitividade entre as áreas de conhecimento(P3), os resultados também revelam concordância majoritária, uma vez que, dos 5 respondentes, 3 concordam com a assertiva, o que evidência que 2 respondentes discordam ou não têm opinião sobre a questão.

Por outro lado, com relação ao modelo de avaliação discriminar o programa pelo caráter homogeneizador (P6), verifica-se divergência na percepção dos coordenadores, uma vez que, dos 5 respondentes, somente 2 concordam com a assertiva, portanto 3 discordam ou não têm opinião sobre a questão. Quando foi solicitado ao respondente da área de ciências exatas e da terra que fizesse as considerações pertinentes sobre a avaliação dos programas mediante a classificação por ranking, nessa linha de raciocínio, um dos coordenadores relatou: "Existem relatos de decisões políticas que não refletem a métrica da avaliação, prejudicando programas. Não concordo com esse filtro político" (coordenador 5, ciências exatas e da terra).

Com relação à área de conhecimento ciências agrárias, constata-se boa aceitação do modelo de avaliação da CAPES com base na classificação dos programas por ranking, uma vez que, das 6 proposições ( $\mathrm{P} 1$ a $\mathrm{P} 5$ ), os resultados revelam que os 4 respondentes dessa área consideram que: i) a avaliação com base na hierarquização identifica pontos fortes e fracos, regulando melhor o desempenho do programa; ii) auxilia a gestão na tomada de decisão para ações de melhoria. Enquanto que 3 respondentes concordam que esse modelo de avaliação: i) reflete a qualidade dos programas, definindo quem são os melhores; ii) estimula de forma positiva a competitividade e iii) atribui pesos adequados aos itens avaliados. Neste último caso (P5), um único respondente aponta razões para discordar, quais sejam:

A produção intelectual tem um peso elevado e a classificação da CAPES, dentro das Ciências Agrárias 1, por exemplo, não considera que em alguns programas os dados são obtidos com menor rapidez do que em outros (coordenador 3 , ciências agrárias).

Considero a ponderação dos itens avaliados inadequada, por exemplo na área de ciências agrárias, uma patente licenciada (vendida pela IES, gerando emprego e renda), vale menos do que um artigo B3 na qualis da CAPES. Isto demonstra total descaso com o que é importante para a sociedade, pois é muito mais valorizado artigos que em sua maioria são "pesquisa de prateleira"!! (coordenador 4, ciências agrárias).

Além disso, os respondentes da área de ciências agrárias apontam que o modelo de avaliação da CAPES não discrimina o programa pelo caráter homogeneizador da avaliação, 
uma vez que os resultados revelam que, dos 4 respondentes, apenas 1 concorda com a assertiva.

Ao analisar a área ciências biológicas, verifica-se que o modelo de avaliação, com base na hierarquização dos programas, é majoritariamente aceito pelos 4 respondentes da área. Tal conclusão se deve ao fato de que os resultados revelam "Concordância" conforme assinalado por 3 dos 4 respondentes, os quais apontam que o modelo de avaliação da CAPES: i) reflete a qualidade do programa; ii) identifica pontos fortes e fracos; iii) auxilia na tomada de decisão e atribui pesos adequados a cada um dos itens avaliados.

No entanto, em relação ao resultado da proposição (P3), há divergência de opinião, uma vez que, dos 4 respondentes, a metade deles, ou seja, 2 concordam que o modelo de avaliação estimula a competitividade positiva e 2 respondentes discordam ou não têm opinião formada. Da mesma forma acontece com a proposição (P6), que, na percepção dos coordenadores, 2 respondentes entendem que o modelo de avaliação da CAPES discrimina o programa pelo seu caráter homogeneizador, enquanto 2 respondentes discordam ou não têm opinião sobre a questão.

No que diz respeito à área de engenharias, percebe-se que o modelo de avaliação, com base na hierarquização dos programas, tem alta aceitação, uma vez que prevalece a frequência de "Concordância" (majoritária nas proposições P1 a P5), incluindo a assertiva relativa ao aspecto de a hierarquização estimular de forma positiva a competitividade entre as áreas de conhecimento, na qual, dos 7 respondentes, 5 concordam com a assertiva, somente 2 discordam da assertiva ou não têm opinião formada. Em relação à proposição (P6), na percepção dos coordenadores, verifica-se que, dos 7 respondentes, 3 entendem que o modelo de avaliação da CAPES discrimina o programa pelo seu caráter homogeneizador; por outro lado, 4 discordam ou não têm opinião sobre a questão.

Embora tenham sido selecionados 6 coordenadores como sujeitos participantes da pesquisa na área de ciências da saúde, somente 2 coordenadores dispuseram-se a responder ao questionário. Os 2 coordenadores respondentes apresentaram um posicionamento positivo em relação ao modelo de avaliação da CAPES com base na hierarquização dos programas, uma vez que ambos concordam plenamente que a avaliação, mediante o escalonamento de pesos e notas: i) reflete a qualidade do programa; ii) identifica pontos fortes e fracos; iii) auxilia a gestão na tomada de decisão; iv) estimula a competitividade positiva; v) considera adequados os pesos atribuídos a cada um dos itens avaliados. 
Por outro lado, estes dois inquiridos destacam que esta forma de avaliação discrimina o programa pelo caráter homogeneizador de seu modelo. Esta crítica pode ser observada no relato de um coordenador de programa dessa área, o qual comenta que a padronização dos critérios de avaliação desconsidera as diferenças regionais: "O Brasil é um país de dimensões continentais. As avaliações precisam levar em consideração as diferenças regionais" (coordenador 11, ciências da saúde).

$\mathrm{Na}$ área de ciências sociais aplicadas, constata-se que o modelo de avaliação, com base na hierarquização dos programas, é, no geral, aceito pelos respondentes dessa área. Entretanto, há uma parcela que critica o modelo em alguns pontos. Percebe-se crítica à classificação dos programas por ranking, nos resultados apontados pelos 7 respondentes: i) somente 3 participantes concordam que o modelo de avaliação da CAPES estimule positivamente a competividade (P3). Nesse caso, evidencia-se, de forma majoritária, que 4 participantes discordam ou não têm opinião formada, quanto ao modelo de avaliação da CAPES estimular positivamente a competividade; ii) 4 respondentes concordam que a atribuição dos pesos aos itens avaliados seja adequada (P5). Por outro lado, 3 discordam ou não têm opinião formada; iii) 6 concordam majoritariamente que o modelo de avaliação discrimina o programa pelo seu caráter homogeneizador.

O resultado obtido com a proposição P6 é reforçado pelo relato do respondente: "O ranking tende a padronizar critérios, que, no caso de cursos de Mestrado e Doutorado, variam enormemente em função da localização geográfica, se é IES pública ou privada, do porte e reputação da IES, dentre outros" (coordenador 25, ciências sociais aplicadas).

Situação similar ao que ocorreu com a área de conhecimento das ciências da saúde registrou-se na área de ciências humanas, que mesmo contando com 6 coordenadores como sujeitos da pesquisa, somente um coordenador respondeu ao questionário, o que inviabiliza a tentativa de descrição estatística dos dados. Visualizando a tabela 4, constatase que o único respondente da área de ciências humanas apresenta mais posições desfavoráveis sobre o modelo de avaliação com base na hierarquização dos programas.

O participante concorda que o modelo em questão identifica pontos fortes e fracos, além de auxiliar na tomada de decisões de melhoria. Porém, o respondente discorda que a avaliação, mediante o escalonamento de notas e peso, reflete a qualidade do programa, estimula positivamente a competitividade e atribui pesos adequados aos itens avaliados. $O$ respondente ainda concorda que a avaliação discrimina o programa pelo caráter homogeneizador. 
$\mathrm{Na}$ área de linguística, letras e artes, os resultados revelam que o modelo de avaliação da CAPES, com base na hierarquização dos programas por ranking de notas e pesos, é aceito sem restrições pelo único respondente, uma vez que se constata "Concordância" total nas proposições de P1, P2, P4 e P5, conforme mostra a tabela 3. Reforçando o posicionamento favorável à classificação em questão, o participante discorda de que esta forma de avaliação discrimina o programa pelo caráter homogeneizador do modelo de avaliação (P6). A aceitação só não é verificada na proposição P3, que trata do estímulo à competitividade positiva, a respeito da qual o coordenador não soube opinar.

A área multidisciplinar apresenta a mesma situação ocorrida nas áreas de ciências da saúde e ciências humanas, ou seja, dos 7 coordenadores selecionados como sujeitos da pesquisa, somente 2 coordenadores responderam ao questionário. A tabela 3 revela que o modelo de avaliação da CAPES, com base na hierarquização dos programas, é aceito plenamente pelos 2 respondentes dessa área, uma vez que a "Concordância" é majoritária com relação ao escalonamento do modelo de avaliação nas 6 proposições. Como ressalva à aceitação citada, observa-se apenas que um dos respondentes discorda de que o modelo em questão identifica pontos fortes e fracos, além de os dois participantes concordarem que a avaliação discrimina o programa pelo caráter homogeneizador.

Cabe apresentar também o contraponto à tabela anterior. Se naquela estão grupados os que concordavam com os resultados, na tabela a seguir apresenta-se os que discordam. Portanto, a tabela 4 traz a frequência de "discordância" na percepção dos coordenadores da pós-graduação em relação à classificação dos programas por ranking de notas e pesos, agrupados por área de conhecimento. 
Tabela 4 - Frequência de disconcordância na percepção dos coordenadores da pós-graduação stricto sensu da UFC em relação à classificação dos programas por ranking de notas e pesos, agrupados por área de conhecimento

\begin{tabular}{|c|c|c|c|c|c|c|c|c|c|c|c|}
\hline \multirow{2}{*}{\multicolumn{2}{|c|}{ Proposição }} & \multicolumn{9}{|c|}{ Área de conhecimento CAPES } & \multirow{2}{*}{ Total } \\
\hline & & EXT & AGR & BIO & ENG & SAU & CSA & HUM & LLA & MUL & \\
\hline P1 & $\begin{array}{l}\text { Reflete a qualidade do } \\
\text { programa, fazendo a } \\
\text { distinção entre os melhores }\end{array}$ & - & 1 & 1 & - & - & 1 & 1 & - & - & 4 \\
\hline P2 & $\begin{array}{l}\text { Identifica os pontos fortes e } \\
\text { fracos, regulando melhor o } \\
\text { desempenho do programa }\end{array}$ & - & - & 1 & - & - & 1 & - & - & 1 & 3 \\
\hline P3 & $\begin{array}{l}\text { Estimula de forma positiva a } \\
\text { competitividade entre as } \\
\text { áreas de conhecimento }\end{array}$ & 1 & 2 & 2 & 2 & - & 4 & 1 & - & - & 11 \\
\hline P4 & $\begin{array}{l}\text { Auxilia na tomada de } \\
\text { decisões para definição de } \\
\text { ações de melhoria dos } \\
\text { programas }\end{array}$ & - & - & 1 & - & - & 1 & - & - & - & 2 \\
\hline P5 & $\begin{array}{l}\text { Atribui pesos adequados a } \\
\text { cada um dos itens } \\
\text { avaliados: inserção social } \\
\text { (10\%); corpo docente (20\%); } \\
\text { corpo discente (30\%); } \\
\text { produção intelectual (40\%) }\end{array}$ & - & 1 & - & - & - & 3 & 1 & - & - & 5 \\
\hline P6 & $\begin{array}{l}\text { Discrimina o programa pelo } \\
\text { caráter homogeneizador do } \\
\text { modelo de avaliação }\end{array}$ & 2 & 3 & 1 & 2 & - & 1 & - & 1 & - & 10 \\
\hline & $\begin{array}{l}\text { spondentes totais por área } \\
\text { de conhecimento }\end{array}$ & 5 & 4 & 4 & 7 & 2 & 7 & 1 & 1 & 2 & 33 \\
\hline
\end{tabular}

Fonte: Dados da pesquisa (2017).

Legenda: ciência exatas e da terra (EXT); ciências agrárias (AGR); ciências biológicas (BIO); engenharias (ENG); ciências da saúde (SAU); ciências sociais e aplicadas (CSA); ciências humanas, (HUM); linguística, letras e artes (LLA) e multidisciplinar (MUL).

Observa-se que não há "discordância" na maioria das proposições; chama atenção somente a frequência de "discordância" da proposição (P3), uma vez que os resultados revelam que, do total de 33 respondentes, 11 distribuídos em 6 áreas de conhecimentos, quais sejam: ciências exatas e da terra (1), ciências agrárias (1), ciências biológicas (2), engenharias (2), ciências sociais aplicadas (4) e ciências humanas (1), discordam que a classificação dos programas por ranking estimule de forma positiva a competitividade entre as áreas de conhecimento. E, ainda, a frequência da proposição (P6), na qual os resultados revelam que, dos 33 respondentes, 10 distribuídos em 6 áreas de conhecimentos, quais sejam: ciências exatas e da terra (2), ciências agrárias (3), ciências biológicas (1), engenharias (2), ciências sociais aplicadas (1) e linguística, letras e artes (1), discordam que o sistema de avaliação por ranking discrimina o programa pelo caráter homogeneizador do modelo de avaliação da CAPES. 
Também importa apresentar a frequência de desconhecimento que os respondentes informaram, mais uma vez no intento de identificar tais respostas por área de conhecimento. A tabela 5 apresenta a frequência de "desconhecimento" na percepção dos coordenadores da pós-graduação em relação à classificação dos programas por ranking de notas e pesos, respondentes estes mais uma vez agrupados por área de conhecimento.

Tabela 5 - Frequência de desconhecimento na percepção dos coordenadores da pós-graduação stricto sensu da UFC em relação à classificação dos programas por ranking de notas e pesos, agrupados por área de conhecimento

\begin{tabular}{|c|c|c|c|c|c|c|c|c|c|c|c|}
\hline \multirow{2}{*}{\multicolumn{2}{|c|}{ Proposição }} & \multicolumn{9}{|c|}{ Área de conhecimento CAPES } & \multirow{2}{*}{ Total } \\
\hline & & EXT & AGR & $\mathrm{BIO}$ & ENG & SAU & CSA & HUM & LLA & MUL & \\
\hline P1 & $\begin{array}{l}\text { Reflete a qualidade do } \\
\text { programa, fazendo a } \\
\text { distinção entre os melhores }\end{array}$ & - & - & - & - & - & - & - & - & - & - \\
\hline P2 & $\begin{array}{l}\text { Identifica os pontos fortes e } \\
\text { fracos, regulando melhor o } \\
\text { desempenho do programa }\end{array}$ & - & - & - & - & - & - & - & - & - & - \\
\hline P3 & $\begin{array}{l}\text { Estimula de forma positiva a } \\
\text { competitividade entre as } \\
\text { áreas de conhecimento }\end{array}$ & 1 & - & - & - & - & - & - & 1 & - & 2 \\
\hline P4 & $\begin{array}{l}\text { Auxilia na tomada de } \\
\text { decisões para definição de } \\
\text { ações de melhoria dos } \\
\text { programas }\end{array}$ & - & - & - & - & - & - & - & - & - & - \\
\hline P5 & $\begin{array}{l}\text { Atribui pesos adequados a } \\
\text { cada um dos itens } \\
\text { avaliados: inserção social } \\
\text { (10\%); corpo docente (20\%); } \\
\text { corpo discente (30\%); } \\
\text { produção intelectual (40\%) }\end{array}$ & - & 1 & 1 & 1 & - & - & - & - & - & 3 \\
\hline P6 & $\begin{array}{l}\text { Discrimina o programa pelo } \\
\text { caráter homogeneizador do } \\
\text { modelo de avaliação }\end{array}$ & 1 & 3 & 1 & 2 & - & - & - & - & - & 7 \\
\hline & $\begin{array}{l}\text { pondentes totais por área de } \\
\text { eecimento }\end{array}$ & 5 & 4 & 4 & 7 & 2 & 7 & 1 & 1 & 2 & 33 \\
\hline
\end{tabular}

Fonte: Dados da pesquisa (2017).

Legenda: ciência exatas e da terra (EXT); ciências agrárias (AGR); ciências biológicas (BIO); engenharias (ENG); ciências da saúde (SAU); ciências sociais e aplicadas (CSA); ciências humanas, (HUM); linguística, letras e artes (LLA) e multidisciplinar (MUL).

Ao analisar a tabela 5, observa-se que a frequência de desconhecimento, ou seja, da opção não sei, não é representativa, uma vez que, na maioria das áreas, a frequência varia de 0 a 3 respondentes. Apenas destaca-se a proposição (P6), na qual 7 respondentes distribuídos em 4 áreas de conhecimentos: ciências exatas e da terra (1), ciências agrárias (3), ciências biológicas (1) e engenharias (2) revelam que não têm opinião formada sobre a classificação dos programas por ranking discriminar o programa pelo caráter homogeneizador do modelo de avaliação da CAPES. 
Em síntese, na percepção dos coordenadores de pós-graduação stricto sensu da UFC, que responderam ao questionário da pesquisa, o resultado geral das respostas revela que o modelo de avaliação adotado pela CAPES, com base na classificação de programas hierarquizados por notas e peso, é bem aceito, como pode ser visto na frequência de "concordância" majoritária nas proposições: (P1) reflete a qualidade do programa, com distinção dos melhores; (P2) identifica pontos fortes e fracos; (P4) auxilia na tomada de decisão e (P5) atribui pesos adequados a cada um dos itens avaliados.

O resultado da pesquisa também revela que as críticas ao modelo de avaliação concentram-se na padronização dos critérios de avaliação da CAPES (P6), que desconsidera as diferenças regionais tão visíveis no Brasil, e no grau de discordância com relação à avaliação da CAPES estimular a competitividade positiva entre as áreas de conhecimento (P3). Alguns entendem essa forma de avaliação não como a melhor, mas como a necessária, como relata o coordenador 34 (área de conhecimento não identificada): "Apesar de achar que não é o único mecanismo de análise, não vejo outro".

O resultado geral do modelo de avaliação da CAPES apresentou maiores índices de aceitação em relação aos resultados das avaliações por área. A análise dos resultados de forma detalhada demonstrou diferenças significativas na percepção dos gestores participantes da pesquisa de cada uma das 9 áreas de conhecimento, notadamente nas áreas de conhecimento de ciências humanas e ciências sociais aplicadas, permitindo identificar que, nas áreas classificadas como ciências "brandas," as críticas ao sistema de avaliação da CAPES foram mais contundentes.

Os resultados revelam que os inquiridos consideram que o modelo de avaliação, com base no escalonamento de nota e peso, reflete a qualidade do programa (P1), uma vez que quase a totalidade dos respondentes concordam plenamente com a afirmativa. Da mesma forma, a grande maioria concorda que o escalonamento regula o desempenho do programa, permitindo identificar pontos fortes e fracos (P2). Por sua vez, a frequência de "concordância" em relação ao modelo de avaliação, auxiliar a gestão na tomada de decisões para definição de ações de melhoria dos programas beira à unanimidade (P4).

Os resultados revelam, ainda, que os respondentes discordam de forma majoritária de que o modelo de avaliação da CAPES estimule de forma positiva a competitividade (P3), especialmente as áreas de ciências humanas e ciências sociais aplicadas, áreas típicas das ciências "brandas", e até mesmo de áreas como as de ciências exatas e da terra, ciências agrárias, ciências biológicas e engenharias. Neste quesito, destaca-se, 
ainda, que o único respondente da área de linguística, letras e artes não têm opinião formada sobre o tema.

Com relação à proposição (P5), atribui pesos adequados a cada um dos itens avaliados, a frequência de "discordância" de maior concentração foi nas áreas das ciências "brandas", ou seja, ciências sociais aplicadas e humanas, além de 1 respondente da área de ciências agrárias.

$E$, por fim, no que se refere à proposição (P6), que faz referência à discriminação do programa pelo caráter homogeneizador do modelo, a avaliação dos respondentes foi acentuadamente desfavorável ao modelo de avaliação da CAPES. Das 9 áreas de conhecimento, somente a área de ciências agrárias e a linguística, letras e artes não consideram que o modelo de avaliação da CAPES discrimine o programa.

Diante do exposto, percebe-se que o modelo de avaliação da CAPES, na percepção dos coordenadores, a despeito das críticas, é aceito pela comunidade acadêmica investigada. As críticas ao modelo concentram-se de forma mais acentuada nas áreas classificadas como ciências "brandas" e de forma mais leve nas áreas classificadas como ciências "duras". Evidencia-se que a variação do índice de "Concordância/Discordância" pode ser maior ou menor, mais ou menos representativo, dependendo da visão de mundo do respondente, do aspecto epistemológico e filosófico da área de conhecimento.

A respeito disso, Dias Sobrinho (2012) considera que a avaliação é polissêmica, aberta e carregada de valores plurais e contraditórios; a avaliação educativa põe em questão os significados dos fenômenos educativos que são sempre multidimensionais. Dessa forma, "a avaliação deve envolver, necessariamente, o trabalho interpretativo da comunidade acadêmica, que é sempre contraditória, mas que também pode comportar objetivos comuns para além dos valores diferentes" (2009, p. 138). O autor diz ainda que na avaliação é possível enxergar a predominância de dois paradigmas distintos: de um lado, as ciências "duras", que operam com a explicação, pretendendo mostrar verdades acabadas, e, de outro, as ciências "brandas", que tratam da complexidade das ciências humanas e sociais, sem negar os recursos explicativos.

\section{CONSIDERAÇÕES FINAIS}

O presente estudo possibilitou responder de que forma a avaliação externa promovida pela CAPES é percebida pelos programas de pós-graduação avaliados, tomando-se uma universidade federal como lócus. É possível concluir que grande parte dos programas de pós-graduação da UFC aceita bem a classificação hierarquizada por notas e 
pesos promovida pela CAPES. Os programas tecem críticas aos critérios adotados pela agência que desconsidera as diferenças regionais num país tão heterogêneo e tão cheio de desigualdades regionais na oferta e na qualidade dos cursos como o Brasil. Ainda, os programas criticam o estímulo promovido pela CAPES para gerar uma competitividade positiva entre as áreas de conhecimento, não sendo uma política solidária, especialmente para programas com dificuldades para se consolidar.

\section{REFERÊNCIAS}

AGUILAR, M. J., \& ANDER-EGG, E. Avaliação de serviços e programas sociais. 2. ed. Petrópolis: Vozes, 1994.

BAZERMAN, M. Processo decisório. Rio de Janeiro: Elsevier, 2014.

BRASIL. Constituição da República Federativa do Brasil. Brasília: Senado Federal, 1988.

BRASIL. Lei no 9.394, de 20/12/1996. Estabelece as diretrizes e bases da educação nacional, 1996b.

BRASIL. Lei 10.861 de 14/04/2004. Institui o Sistema Nacional de Avaliação da Educação Superior SINAES e dá outras providências, 2004.

BRASIL. (2010). Plano Nacional de Pós-Graduação - PNPG 2011-2020. Brasília, DF. CAPES, v1.

CAPES. 50 anos: depoimentos ao CPDOC/FGV. Brasília: CAPES, 2002.

DIAS SOBRINHO, J. (2003a). Avaliação da educação superior: regulação e emancipação. In J. Dias Sobrinho \& D. Ristoff (Orgs.). Avaliação e compromisso público: a educação superior em debate. Florianópolis: Insular.

DIAS SOBRINHO, J. Avaliação: políticas educacionais e reformas da educação superior. São Paulo: Cortez, 2003.

DIAS SOBRINHO, J. Universidade: processos de socialização e processos pedagógicos. In N. C. Balzan \& J. Dias Sobrinho (Orgs.), Avaliação institucional: teoria e experiências (pp. 15-36). São Paulo: Cortez, 2008.

DIAS SOBRINHO, J. Avaliação da Educação Superior: conflito de paradigmas. Fórum da Gestão do Ensino Superior nos Países e Regiões de Língua Portuguesa. Macau, 2012.

HAMMOND, J. S., KEENEY, R. L., \& RAIFFA, H. Decisões inteligentes. Rio de Janeiro: Elsevier, 2017. 
MCGEE, J., \& PRUSAK, L. Gerenciamento estratégico da informação: aumente a competitividade e a eficiência da sua empresa utilizando a informação como ferramenta estratégica. Rio de Janeiro: Campus, 1994.

SOUSA, E. C. B. M., \& SOUSA E. M. Avaliação de instituições de ensino superior: o caso do Brasil e de outros países. In J. Stark, E. C. B. M. Souza \& E. M. Sousa, Avaliação em instituições de ensino superior (pp. 63-110). Brasília: Universidade de Brasilia, 1998.

Artigo recebido em: 02 de outubro de 2019 Aceito para publicação em: 27 de novembro de 2020 